\title{
AVALIAÇÃO DA QUALIDADE DAS ÁGUAS SUBTERRÂNEAS EM FORTALEZA-CEARÁ
}

\author{
10.18190/1980-8208/estudosgeologicos.v28n2p68-81 \\ 1.Instituto Federal do Espírito Santo ediulemos@ yahoo.com.br \\ 2. Universidade Federal do Ceará itabaracicavalcante@gmail.com; \\ flaviopinheiro@hotmail.com
}

Ediu Carlos Lopes Lemos ${ }^{1}$

Itabaraci Nazareno Cavalcante ${ }^{2}$

Flávio Costa Pinheiro ${ }^{2}$

\section{RESUMO}

Esta pesquisa objetivou avaliar a qualidade das águas subterrâneas do município de Fortaleza, capital do Estado do Ceará. A metodologia constou de revisão bibliográfica, análises físico-químicas das águas de 99 poços tubulares, geração de mapas temáticos de isovalores de $\mathrm{pH}, \mathrm{STD}, \mathrm{CE}$, cloretos e nitrato. Os resultados mostram uma condutividade elétrica média de $623 \mu \mathrm{S} / \mathrm{cm}$ a $25^{\circ} \mathrm{C}$ e STD com baixa a média salinidade. Quanto à dureza, 50\% são águas "dura" a "muito dura", 18\% "pouco dura" e 32\% do tipo "branda". O maior problema das águas está na concentração por nitrato, onde 25,5\% das amostras analisadas apresentam valores que ultrapassam em até $460 \%$, o limite recomendado pela Portaria 2914/2011 do Ministério da Saúde. Observa-se em função da relação iônica entre ânions e cátions, de $\mathrm{Cl}^{-}>\mathrm{HCO}_{3}{ }^{-}>\mathrm{SO}_{4}{ }^{2-}$ e $\mathrm{Na}^{+}>\mathrm{Mg}^{2+}>\mathrm{Ca}^{2+}$.

Palavras chave: Hidroquímica, qualidade da água, poços tubulares

\section{ABSTRACT}

This research aimed to assess the quality of groundwater in the city of Fortaleza, capital city of Ceará. The methodology consisted of literature review, physical-chemical analysis of the water from 99 tubular wells, generation of thematic maps of $\mathrm{pH}$ isovalues, STD, $\mathrm{EC}$, and chlorides and nitrate. The results show an average electrical conductivity of 623 $\mu \mathrm{S} / \mathrm{cm}$ at $25^{\circ} \mathrm{C}$ and STD with low to medium salinity. Regarding the hardness, $50 \%$ of the waters are "hard" to "very hard", 18\% "little hard" and $32 \%$ of the "bland" type. The biggest problem of the waters lies on the concentration by nitrate, in which $25.5 \%$ of the analysed samples present values that exceed by up to $460 \%$, the recommended limit by the Decree 2914/2011 of the Health Ministry. It is observed due the ionic relationship between anions and cations, $\mathrm{Cl}^{-}>\mathrm{HCO}_{3}{ }^{-}>\mathrm{SO}_{4}{ }^{2-}$ and $\mathrm{Na}^{+}>\mathrm{Mg}^{2+}>\mathrm{Ca}^{2+}$.

Keywords: Hydrochemistry, quality of water, tubular wells

\section{INTRODUÇÃO}

Quando o assunto é recurso hídrico, infelizmente, no ensino brasileiro, a água subterrânea não ocupa, na escala de valores, o lugar que lhe é devido, dando-se mais destaque às águas superficiais.

As águas subterrâneas de Fortaleza desempenham um papel importante como recurso complementar e estratégico de reconhecido valor

Estudos Geológicos Vol. 28(2):2018 socioeconômico, pois metade da população se utiliza da água captada destes mananciais face ao baixo custo em relação à água da rede de distribuição e ao valor estratégico nos períodos de estiagem (Tajra, 2001).

Nos períodos de estiagem, as águas subterrâneas são utilizadas como uma alternativa para suprir a demanda da população. Porém, a falta de critérios na construção destes poços, associada ao desconhecimento da geologia local, 
poderá aumentar o risco à contaminação físico-química e bacteriológica nos aquíferos captados.

Neste trabalho, é feita uma avaliação da qualidade das águas subterrâneas do município de Fortaleza, buscando se identificar anomalias nos parâmetros físico-químicos que possam significar a degradação da qualidade destas águas, bem como, destacar as características hidroquímicas e de potabilidade em conformidade com as normas e padrões estabelecidos pelo Ministério da Saúde (MS).

O município de Fortaleza está situado na zona litorânea da porção nordeste do estado do Ceará, Região Nordeste do Brasil, sendo delimitado pelas coordenadas UTM 9565000 a 9595000 Norte e 540000 a 567000 Leste, incluso na folha AS-24-Z-C-IV (SUDENE), possuindo $313,8 \mathrm{~km}^{2}$.

\section{METODOLOGIA DE TRABALHO}

A metodologia adotada na elaboração deste trabalho segue um conjunto de atividades distintas, porém inter-relacionadas, seguindo uma sequência lógica de conhecimentos, resultando, assim, na melhor interpretação de dados.

\section{Revisão bibliográfica e documental}

A revisão bibliográfica sobre a área de estudo constou da obtenção de dados referentes à geologia, hidrogeologia, aspectos socioeconômicos e geoambientais, além de mapas temáticos. Esta pesquisa foi realizada junto aos órgãos públicos como Serviço Geológico do Brasil (CPRM), Fundação Cearense de Meteorologia e Recursos Hídricos (FUNCEME), Superintendência de Obras Hidraúlicas (SOHIDRA), Companhia de Gestão dos Recursos Hídricos (COGERH), Companhia de Águas e Esgotos do Estado do Ceará (CAGECE) e Instituo Brasileiro de Geografia e Estatística
(IBGE), servindo esses dados para um melhor conhecimento das características da área e ajudando na elaboração de base preliminar de trabalho. Posteriormente, foi realizada uma revisão documental de trabalhos já realizados no município e, destaca-se alguns de caráter hidrogeológico e de qualidade das águas subterrâneas, como será mostrado a seguir.

Silva Neto (2010) avaliou as características físico-químicas das águas subterrâneas nos bairros Engenheiro Luciano Cavalcante, Jardim das Oliveiras, Cidade dos Funcionários e Aerolândia, localizados em Fortaleza, que estão inseridos nos Sistemas Hidrogeológico Dunas/Paleodunas, Aluvião e Barreiras, constatando que algumas destas águas têm concentrações iônicas acima dos padrões de potabilidade estabelecidos pela portaria $\mathrm{n}^{\circ}$ 2914/2011, principalmente, quanto aos valores de nitrato (42\%) e ferro $(36 \%)$.

\section{Compilação dos dados de poços e análises físico-químicas}

Foi feita uma compilação de dados de trabalhos realizados junto ao Laboratório de Hidrogeologia da Universidade Federal do Ceará no período de 2010 a 2017, sendo utilizado dados de 99 análises físico-químicas de poços cadastrados no município além, de dados lito-construtivos hidrogeológicos dos poços, bem como, ter subsídios para uma análise quanto à constituição físico-química das águas subterrâneas no município.

\section{Tratamento dos dados}

A qualidade dos resultados das análises químicas foi avaliada mediante $\mathrm{o}$ cálculo do erro da análise através do balanço iônico. Em um balanço iônico ideal, a concentração de cátions deve ser igual a concentração de ânions.

$\mathrm{Na}$ prática existe uma diferença nessas concentrações em decorrência dos 
erros acumulados de cada uma das determinações individuais. O erro prático da análise (e\%) definido por Logan
(1965) in Santos (1997) pode ser obtido pela aplicação da equação 1 .

$$
\text { 1) } e^{e}=\left|\frac{r \varepsilon p-r \varepsilon n}{r \varepsilon p+r \varepsilon n}\right| \times 100 \quad \text { (equação }
$$

Onde: r\&p é o valor absoluto do somatório de cátions (meq/L) e r\&n é o valor absoluto do somatório de ânions (meq/L).

O erro admissível depende da concentração dos íons e da classificação iônica, haja vista que uma água com baixa concentração de sais é muito difícil de ser avaliada com precisão. Para se verificar a qualidade das análises de água alguns autores consideram a condutividade elétrica e outros a concentração dos íons em miliequivalente por litro. Para os resultados das análises obtidas, neste estudo, foi considerado um erro admissível de $10 \%$.

A partir daí, foram elaborados gráficos hidroquímicos, com a utilização do programa computacional QualiGraf (Möbus, 2003), disponível no site da Fundação Cearense de Meteorologia (FUNCEME), e a elaboração de mapas de zoneamento para os seguintes parâmetros: CE, pH, STD, Cloretos e Amônia com a utilização do programa Surfer.

Como referências para avaliar a qualidade das águas subterrâneas, foram considerados os limites de potabilidade apresentados pela Portaria n $^{\circ} 2914$, de 12 de dezembro de 2011 do Ministério da Saúde combinado ao uso do diagrama de Schöller \& Berkaloff. Foi realizada uma classificação química das águas em relação aos íons maiores através do diagrama de Piper.

\section{RESULTADOS E DISCUSSÕES}

As propriedades físico-químicas são importantes no que se referem à qualificação das águas, definidas pela sua composição e pelo conhecimento dos efeitos a saúde que podem causar seus constituintes.

As mudanças na composição química das águas subterrâneas são caracterizadas por dois tipos de reações químicas: dissolução da superfície das rochas e precipitação das substâncias dissolvidas nas águas, ambas sendo importantes no intemperismo químico, ou seja, na decomposição da rocha por ação química.

$\mathrm{Na}$ área de estudo, os valores de condutividade elétrica obtidos apresentam média geral de $623 \mu \mathrm{S} / \mathrm{cm}$ a $25^{\circ} \mathrm{C}$, sendo que, de 99 dados, $8(8 \%)$ encontram-se com valores superiores a $1.000 \mu \mathrm{S} / \mathrm{cm}$, chegando ao máximo de $2050 \mu \mathrm{S} / \mathrm{cm}$ (Figura 1). Observa-se que os maiores valores de condutividade elétrica se encontram na porção sudoeste de Fortaleza, congruente a Bacia do rio Maranguapinho, onde o solo é do tipo Neossolo Flúvico e vegetação de carnaubeiras, típica de solos salinos. 


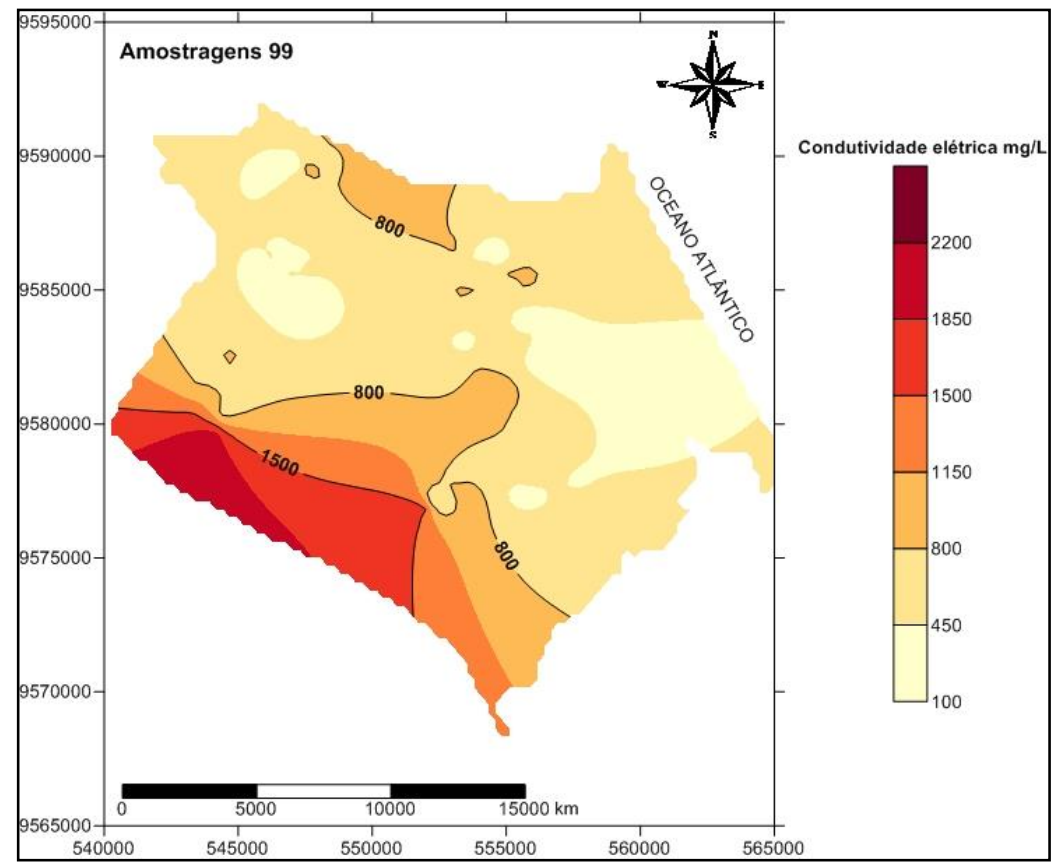

Figura 1 - Distribuição de valores de Condutividade Elétrica (C.E) na área de estudo.

Os valores de STD nas águas subterrâneas da área variaram de 88 a $1508 \mathrm{mg} / \mathrm{L}$. Segundo a Portaria 2914/11 do MS, o valor máximo tolerável é de $1.000 \mathrm{mg} / \mathrm{L}$. A representação da variação dos valores de STD pode ser visualizada na Figura 2, onde se observa uma maior concentração na porção sudoeste onde afloram rochas do Sistema Cristalino.

Segundo Cavalcante (1998), para o cristalino, é comum concentrações de STD oscilando de 500 a 2.000 mg/L, em decorrência da elevada concentração de cloretos presentes nas águas que percolam o meio subterrâneo. $\mathrm{Na}$ área as águas que apresentam concentrações elevadas de sais, provavelmente, são aquelas captadas a partir de fraturas interconectadas com zonas de recarga associada às águas superficiais salinizadas. Observa-se maior concentração de sais dissolvidos na porção sudoeste da área onde o Neossolo Flúvico predomina e possuí dentre suas características drenagem imperfeita, altos teores de sódio, fertilidade muito baixa e é sobreposto por vegetação típica de solos salinos. 
AVALIAÇÃO DA QUALIDADE DAS ÁGUAS SUBTERRÂNEAS...

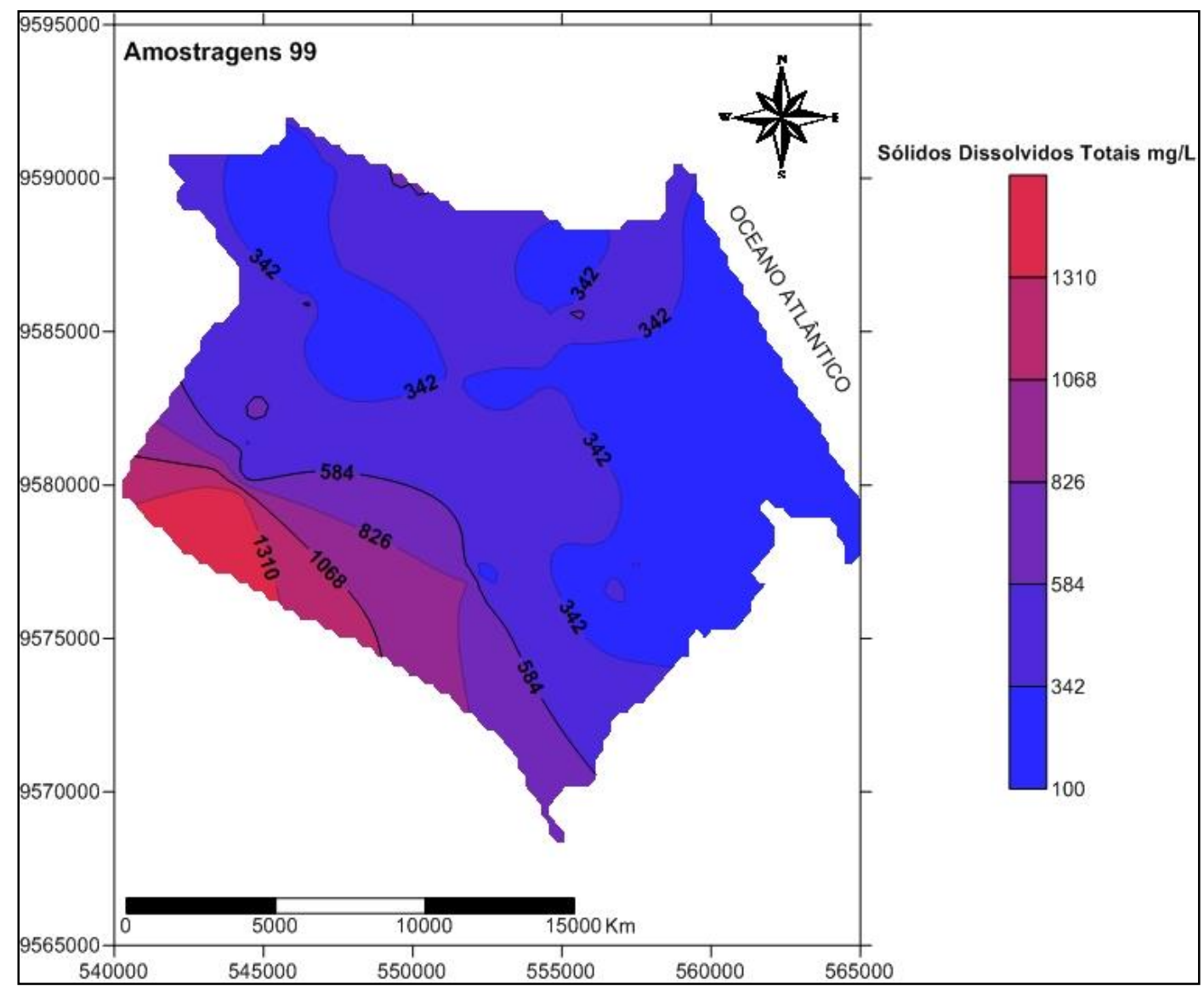

Figura 2 - Distribuição de Sólidos Totais Dissolvidos (STD) na área de estudo

A classificação das águas subterrâneas da área, com relação a sua dureza (teor de $\mathrm{CaCO}_{3} \mathrm{em} \mathrm{mg/L),} \mathrm{a} \mathrm{partir}$ de 99 amostras, revela que $(50 \%)$ das águas possuem características de "dura" a "muito dura", enquanto que $18 \%$ apresentam característica de pouco dura e $(32 \%)$ foi classificada como do tipo "branda" (Fig. 3). Embora os resultados das análises sejam elevados para dureza todas as amostras apresentaram valores dentro do limite de potabilidade estabelecido pela Portaria $n^{\circ} 2914 / 2011$ do Ministério da Saúde (até $500 \mathrm{mg} / \mathrm{L}$ de $\mathrm{CaCO}_{3}$ ).

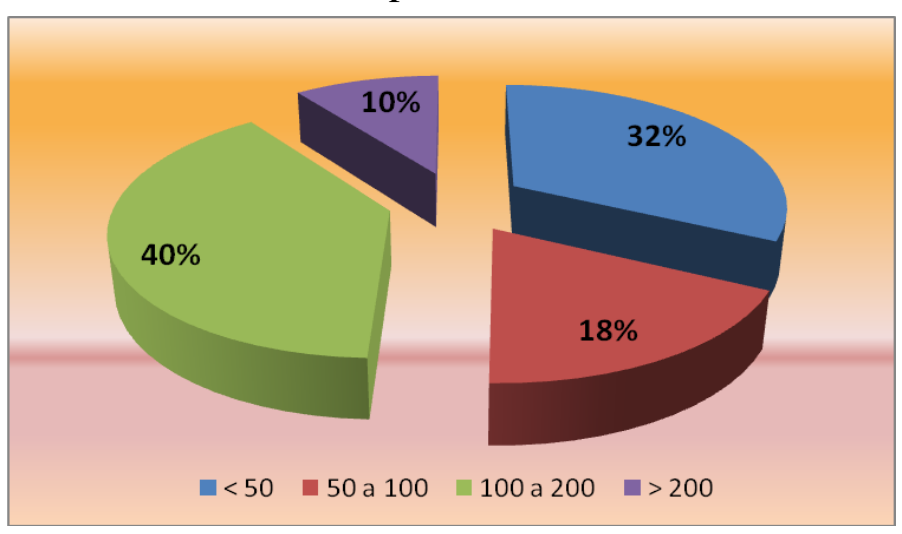

Figura 3 - Variação de $\mathrm{CaCO}_{3}$ nas águas subterrâneas da área de estudo 
Os valores para cloreto nas águas subterrâneas são bastante variáveis (Fig. 4) e, verifica-se que as 99 amostras possuem concentrações de $30 \mathrm{mg} / \mathrm{L}$ a $456 \mathrm{mg} / \mathrm{L}$, chegando a ultrapassar em $180 \%$ o limite máximo recomendável pelo Ministério da Saúde (250mg/L).

A partir do resultado das 99 análises físico-químicas observa-se que os valores de $\mathrm{pH}$ das águas subterrâneas oscilaram entre 4,5 a 8,04 onde 25 amostras $(25,5 \%)$ apresentam um caráter ácido e 74 (74,5\%) um caráter básico não tendo nenhuma amostra que reflita o caráter absolutamente neutro (Fig. 5).

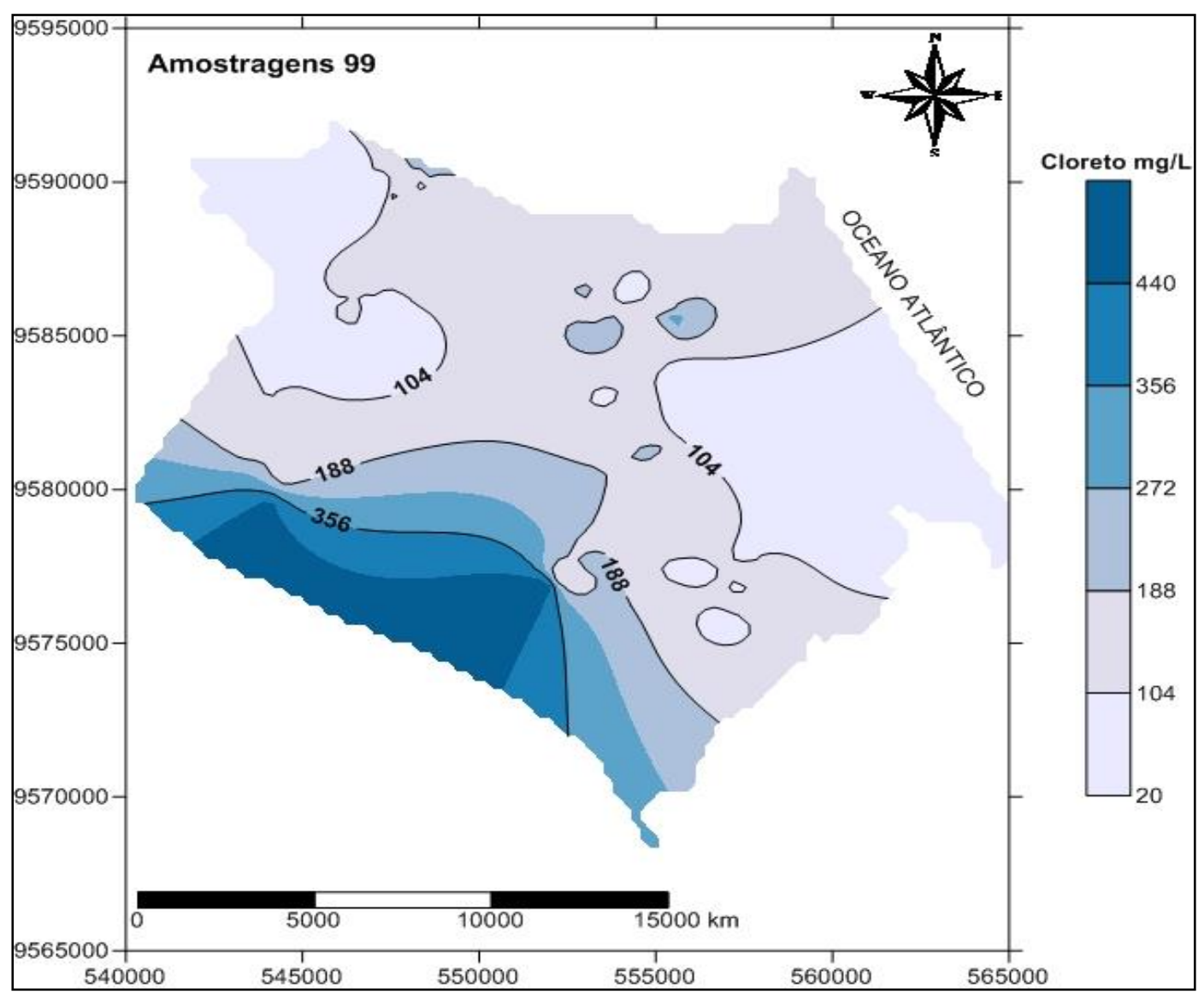

Figura 4 - Distribuição das medidas de Cloreto nas águas subterrâneas da área de estudo 


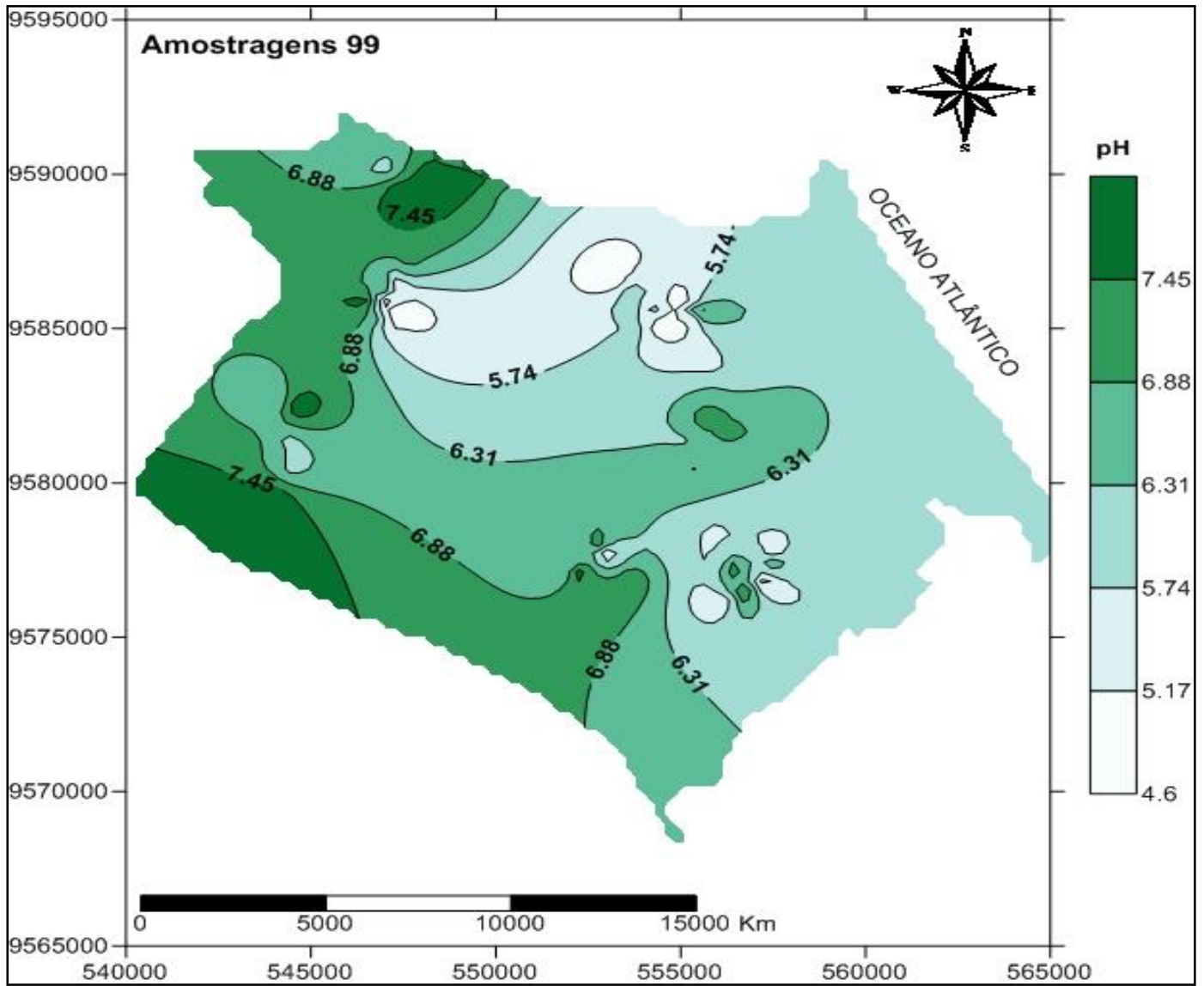

Figura 5 - Distribuição das medidas de pH nas águas subterrâneas da área de estudo.

Dentre as substâncias que podem constituir risco para a saúde humana, incluem-se os compostos de nitrogênio nos seus diferentes estados de oxidação: nitrogênio amoniacal e albuminoide, nitrito e nitrato.

As águas dos 99 poços avaliados na área apresentaram valores de nitrato variando de 0,1 a $46 \mathrm{mg} / \mathrm{L} \mathrm{N}-\mathrm{NO}_{3}$ (Fig. 6); $25,5 \%$ (25) das amostras apresentam valores acima do recomendável para $\mathrm{N}$ $\mathrm{NO}_{3}$, alguns valores chegam a ultrapassar em até $460 \%$, o limite máximo recomendado pelo Ministério da Saúde.

As concentrações elevadas desse elemento são explicadas na medida em que se tem a disposição de efluentes líquidos (esgotos domésticos e industriais) nas águas superficiais que podem interagir com as águas subterrâneas, bem como, no solo através do uso das fossas negras, ausência de saneamento básico e um posicionamento do nível estático muito raso, quase sempre inferior a $07 \mathrm{~m}$, com predominância de 0 a $5 \mathrm{~m}$ e a mercê da variação sazonal.

No sistema digestivo, o nitrato é transformado em nitrosaminas, que são substâncias carcinogênicas. A alguns cientistas advertirem que o excesso de íons de nitrato na água e no alimento pode levar a um aumento na incidência de câncer de estômago. 


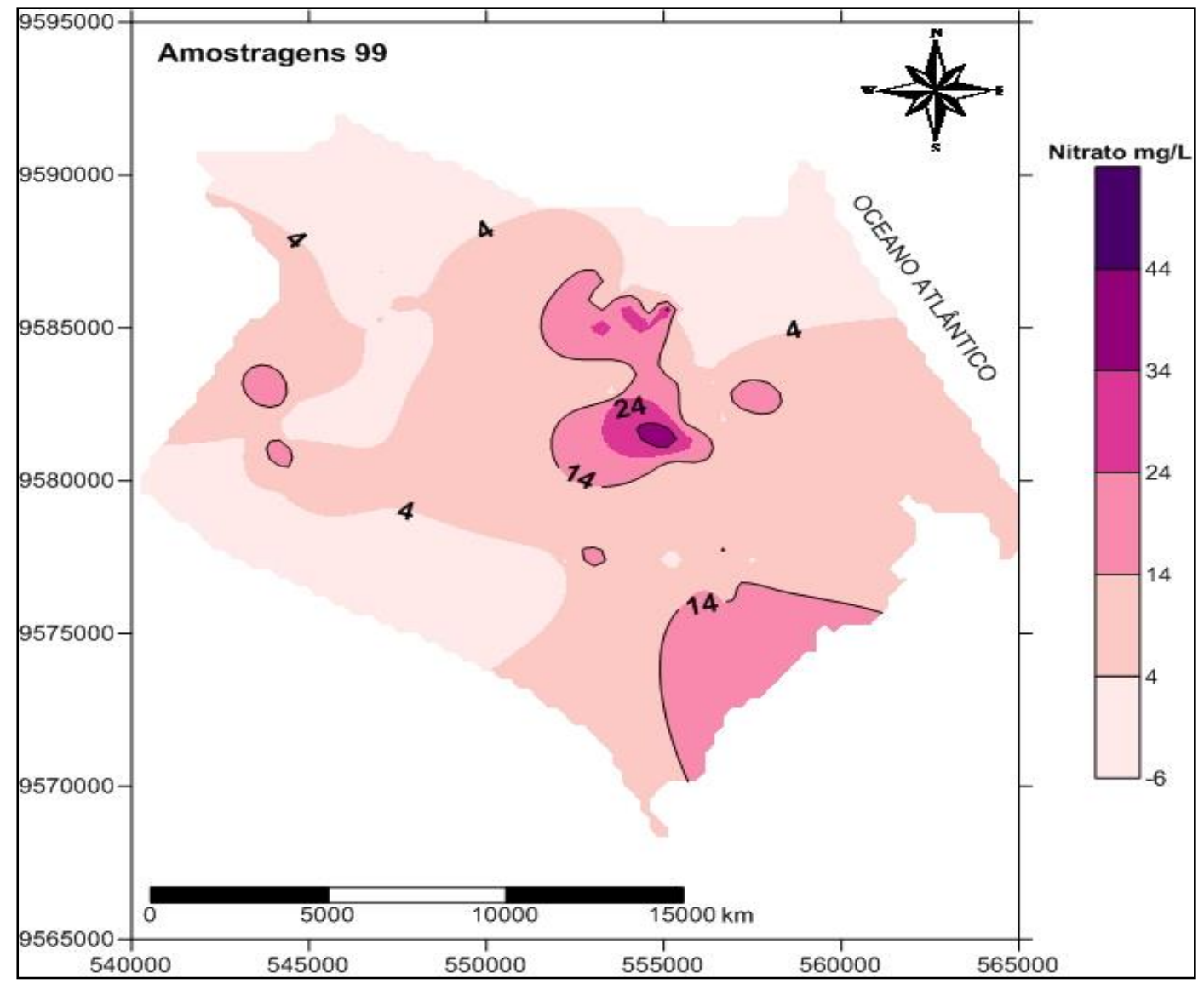

Figura 6 - Distribuição do nitrato nas águas subterrâneas na área de estudo

De acordo com os íons presentes, identificou-se uma predominância no diagrama de Piper das classes cloretadas e sódicas (Fig. 7). Em relação aos cátions, a maior parte é sódica $(94,9 \%)$, seguidas das águas mistas $(5,1 \%)$, para os ânions há uma predominância das águas cloretadas $(56,6 \%)$, seguidas de águas mistas $(22,2 \%)$ e bicarbonatadas $(21,2 \%)$. No geral, as águas são classificadas como cloretadas sódicas, seguidas por bicarbonatadas sódicas.

Há predominância para as águas dessa região, em função da relação iônica entre ânions e cátions, é de $\mathrm{Cl}^{-}>$ $\mathrm{HCO}_{3}{ }^{-}>\mathrm{SO}_{4}{ }^{2-}, \mathrm{Na}^{+}>\mathrm{Mg}^{2+}>\mathrm{Ca}^{2+}$. De acordo com Santos (2000), o predomínio e a presença do cloreto e do sódio nos sistemas aquíferos se dão pelo fato de que, além dos dois elementos correspondentes serem muito abundantes nas águas naturais, possuem solubilidades elevadas, são de difícil precipitação na maioria dos compostos químicos em solução e têm ampla distribuição nos minerais fonte. 


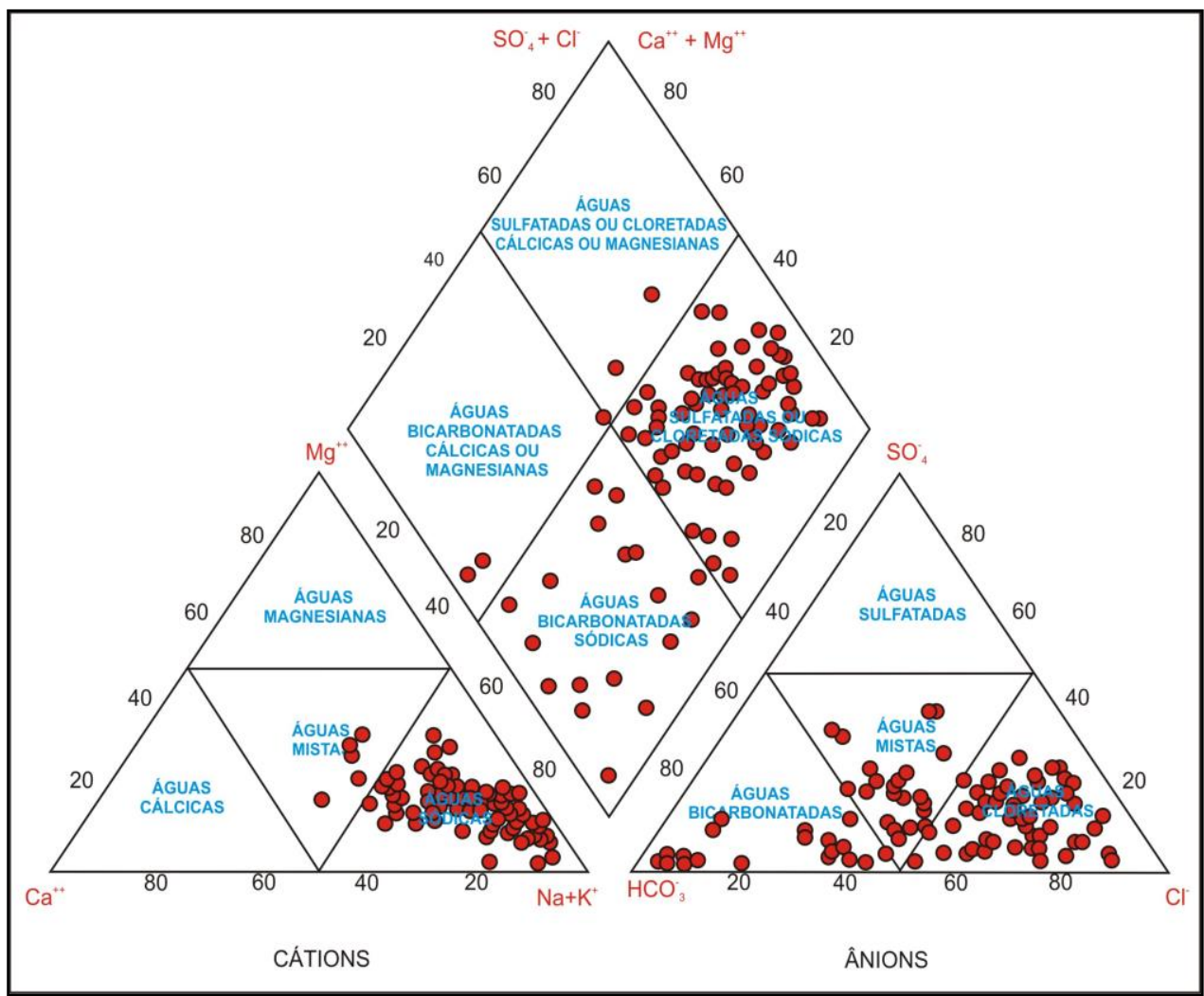

Figura 7 - Classificação iônica pelo Diagrama de Piper os fácies químicos das águas subterrâneas na área.

Em termos de potabilidade, de uma forma geral, os sistemas aquíferos estudados predominam águas com índices aceitáveis do ponto de vista físico-químico, porém, algumas amostras apresentaram concentrações para cloretos que desqualificam estas águas para o consumo humano. A média geral dos demais parâmetros $\left(\mathrm{Ca}^{2+}\right.$, $\mathrm{Mg}^{2+}, \mathrm{Na}^{+}+\mathrm{K}^{+}, \mathrm{Cl}, \mathrm{HCO}_{3}^{-}$), variou entre "Boa" a "Passável", qualificando as águas subterrâneas locais quanto à potabilidade físico-química.

Das 99 análises das águas subterrâneas da área em estudo contidas no Anexo I, observou-se que, para o íon ferro, 69\% delas encontram-se dentro dos padrões de potabilidade da portaria $\mathrm{N}^{\circ}$ 2914\2011 do Ministério da Saúde $(<0,3 \mathrm{mg} / \mathrm{L})$. A tendência à concentração deste íon nas águas subterrâneas locais (31\% das amostras) reflete a influência do nível laterítico da Formação Barreiras, originadas pela reação do óxido de ferro com o oxigênio atmosférico oxidando-se para hidróxido férrico (Cavalcante, 1988; Ribeiro, 2001).

Sabe-se que a elevada concentração de ferro, mesmo que pontual, pode causar problemas ao consumo humano, favorecendo a incidência de problemas cardíacos e diabetes. Segundo Cavalcante (1998), no Estado do Ceará é comum se encontrar elevadas concentrações ( 2 a $15 \mathrm{mg} / \mathrm{L}$ ) do elemento ferro nas águas das aluviões, cujos poços chegam a ceder vazões de até $15 \mathrm{~m}^{3} / \mathrm{h} /$ poço, explotadas para abastecimento público. Nestes casos, se recomenda um tratamento preliminar através de filtros de areia, aeração e filtros com carvão ativado, a fim de se obter uma água potável. 


\section{CONSIDERAÇÕES FINAIS}

De forma geral, as águas subterrâneas de Fortaleza são consideradas como águas potáveis dentro dos padrões estabelecidos pelo Ministério da Saúde, embora apresentem valores anômalos para alguns elementos que podem trazer prejuízos à saúde da população que se utiliza deste recurso no consumo humano. Cita-se, a exemplo, a concentração elevada de ferro e nitrato nestas águas. As águas são classificadas como cloretadas sódicas, seguidas de bicarbonatadas sódicas.

A presença de poços mal construídos, inúmeras vezes sem a técnica necessária, em um ambiente clástico de aquíferos livres e com nível estático freático, muitas vezes subaflorante, convivendo com uma densidade demográfica média de 8.000 $\mathrm{hab} / \mathrm{km}^{2}$, que por longo tempo permaneceu com serviço de esgotamento básico abaixo de 40\%, resultou em problemas qualitativos particularmente para as águas subterrâneas mais rasas.

Diante do exposto sugere-se que sejam feitas análises bacteriológicas e físico-químicas em períodos de estiagem e chuva a fim de se poder analisar a evolução de alguns elementos, bem como, das possíveis fontes de contaminação das águas subterrâneas.

\section{REFERÊNCIAS}

Cavalcante, I. N. 1998. Fundamentos Hidrogeológicos para a Gestão Integrada de Recursos Hídricos na Região Metropolitana de Fortaleza, Estado do Ceará. Tese de Doutoramento. Área de Hidrogeologia. Instituto de
Geociências, Universidade de São Paulo/USP, São Paulo. 153p.

Möbüs, G. - 2003. QUALIGRAF. Programa Para Análise da Qualidade de Água. FUNCEME. http://www.funceme.br/DEHID/in dex.htm. (Acessado em outubro de 2010)

Ribeiro, J.A.F. - 2001 - Características Hidrogeológicas e Hidroquímicas da Faixa Costeira Leste da Região Metropolitana de Fortaleza-CE. Dissertação de Mestrado. Departamento de Geologia/UFC. Fortaleza. 112p.

Santos, A.C., 1997. Noções de Hidroquímica. In: FEITOSA, F.A.C. MANOEL FILHO, J. Hidrogeologia: Conceitos e Aplicações.

Santos, A.C. - 2000 - Noções de Hidroquímica. In: Feitosa, F.A.C. \& Manoel Filho, J. HIDROGEOLOGIA: Conceitos e Aplicações. CPRM - REFO. Fortaleza-CE. Cap.5, p. 81-108, $2^{\mathrm{a}} \mathrm{ed}$.

Silva Neto, R.C. da. 2010. Características fisico-químicas das águas subterrâneas nos bairros aerolândia, engenheiro luciano cavalcante, jardim das oliveiras e cidade dos funcionários, Fortaleza - CE. Relatório de Graduação. Departamento de Geologia da Universidade Federal do Ceará, Fortaleza-CE, 69p.

Tajra, A. A. 2001. Aspectos Técnicoconstrutivos dos poços tubulares e a legislação Pertinente. Área Piloto de Fortaleza-Ceará. Dissertação de Mestrado. Departamento de Geologia da Universidade Federal do Ceará. Fortaleza - CE. 109p. 
ANEXO I

\section{ANAÁLISES FÍSICO-QUÍMICAS DAS ÁGUAS SUBTERRÂNEAS ÁREA DE ESTUDO}

\begin{tabular}{|c|c|c|c|c|c|c|c|c|c|c|c|c|c|c|}
\hline P - 02 & 7.33 & 662 & 98 & 127 & 10 & 133.2 & 5.6 & 4.7 & 1.1 & 0.1 & 16.5 & 0.4 & 9.5 & 344 \\
\hline$P-03$ & 6.67 & 1180 & 116 & 312.7 & 6.0 & 209.5 & 11.2 & 12.5 & 18.7 & 0.1 & 109.8 & 0.5 & 1.5 & 614 \\
\hline$P-04$ & 6.72 & 1611 & 66 & 515 & 5.05 & 190 & 14.5 & 38.4 & 53.3 & 0.05 & 320 & 0.07 & 1.88 & 838 \\
\hline$P-05$ & 8.1 & 693 & 114 & 133 & 17.74 & 100.8 & 18.9 & 17.3 & 13.4 & 0.02 & 100 & 0.08 & 4.14 & 360 \\
\hline$P-06$ & 6.5 & 669 & 69 & 171 & 7.0 & 91.6 & 5.1 & 22 & 16.2 & 0.1 & 123.5 & 0.5 & 1.0 & 348 \\
\hline$P-10$ & 7.11 & 547 & 47 & 113 & 21.29 & 47.9 & 2.1 & 29.8 & 18 & 0.03 & 151 & 0.05 & 7.13 & 284 \\
\hline$P-11$ & 7.45 & 1038 & 169 & 210 & 76.09 & 142 & 12.5 & 49.4 & 29 & 0.02 & 247 & 0.06 & 8.46 & 540 \\
\hline$P-12$ & 8.13 & 917 & 325.3 & 131.8 & 42.2 & 105.1 & 21.6 & 35.2 & 50.9 & ND & 300 & 0.05 & 2.8 & 732.3 \\
\hline$P-13$ & 6.21 & 623 & 99 & 104 & 21 & 68 & 11 & 32 & 14.4 & ND & 140 & 0.05 & 20.1 & 367.4 \\
\hline $\mathrm{P}-14$ & 6.72 & 571 & 135.5 & 127.5 & 19.2 & 81 & 13.7 & 27.2 & 19.2 & ND & 148 & 0.05 & 0.8 & 432.4 \\
\hline$P-15$ & 5.97 & 501 & 51.8 & 109 & 38.1 & 62.7 & 9.3 & 17.6 & 15.4 & ND & 108 & 0.03 & 2.8 & 315.4 \\
\hline$P-16$ & 6.44 & 967 & 197 & 172.7 & 43.4 & 118.4 & 23.9 & 46.4 & 29.8 & 0.5 & 240 & 1.68 & 25 & 659.3 \\
\hline $\mathrm{P}-17$ & 7.16 & 858 & 276 & 143.9 & 25 & 132.6 & 6.4 & 33.6 & 25 & ND & 188 & 0.12 & 3.2 & 675.5 \\
\hline
\end{tabular}


Ediu Carlos Lopes Lemos et al.

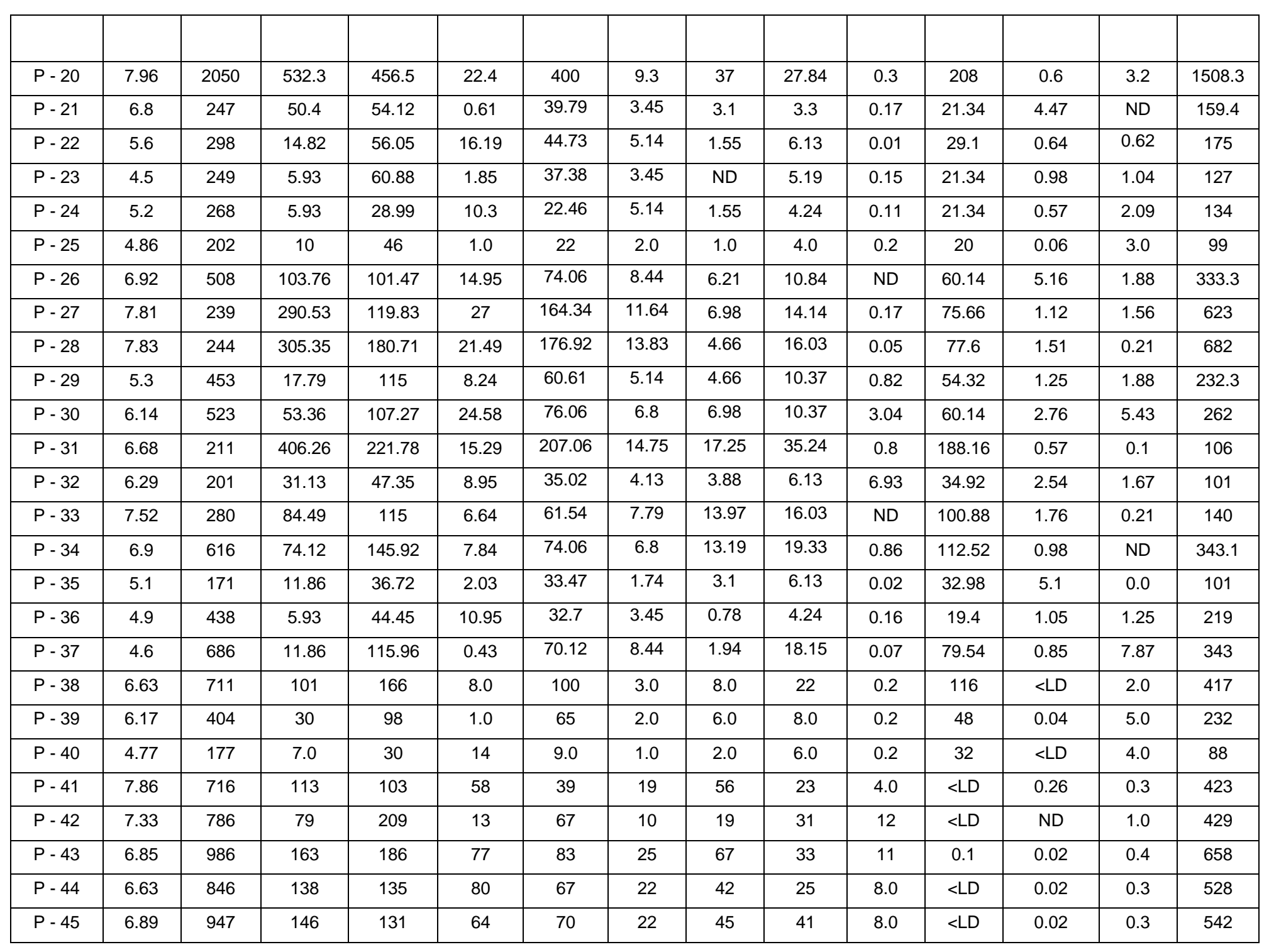

Estudos Geológicos Vol. 28(2):2018

$\underline{\text { www.ufpe.br/estudosgeolgogicos }}$ 
AVALIAÇÃO DA QUALIDADE DAS ÁGUAS SUBTERRÂNEAS...

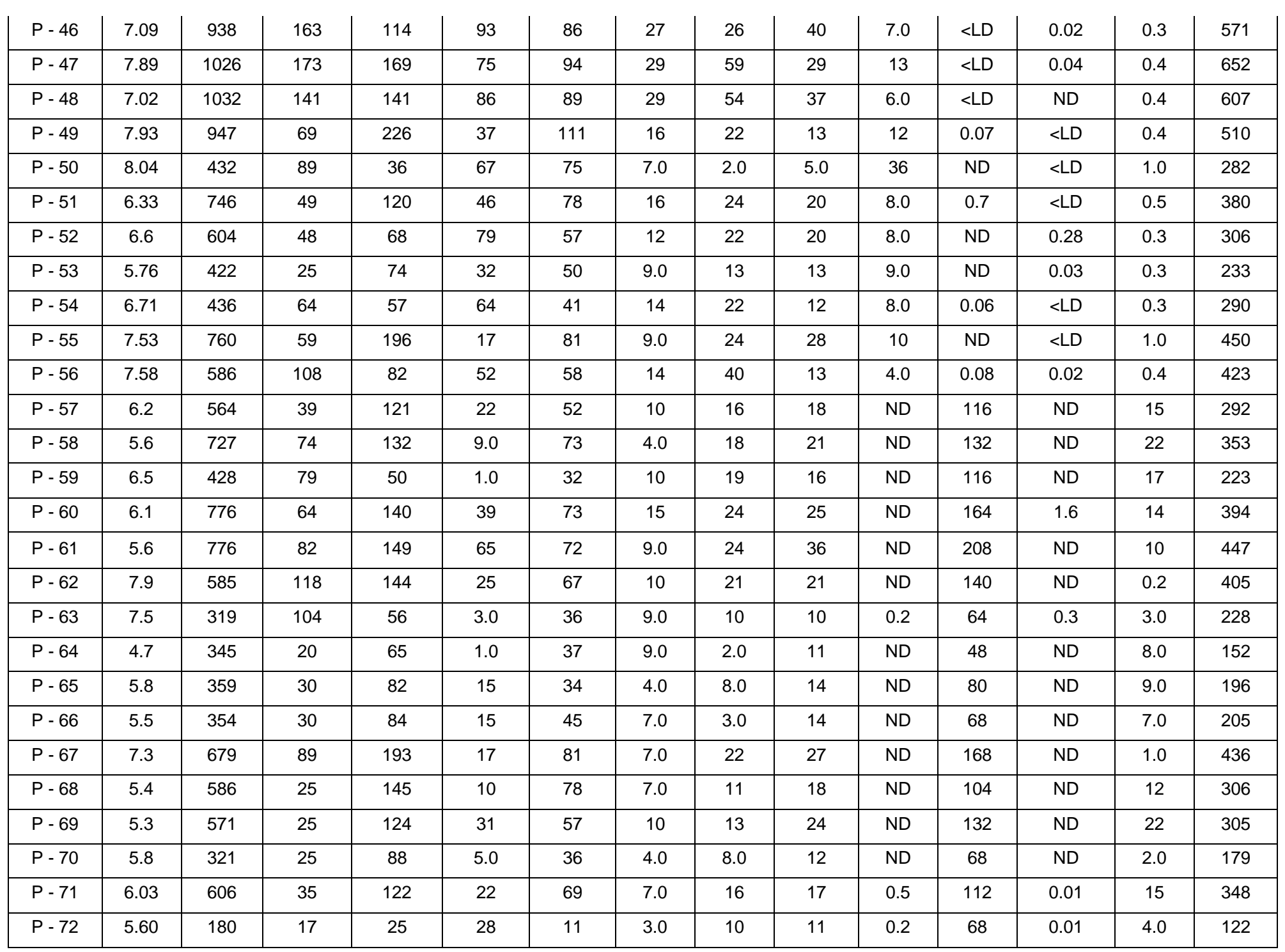


Ediu Carlos Lopes Lemos et al.

\begin{tabular}{|c|c|c|c|c|c|c|c|c|c|c|c|c|c|c|}
\hline P - 73 & 6.41 & 432 & 84 & 50 & 33 & 28 & 8.0 & 24 & 17 & 0.6 & 132 & ND & 22 & 335 \\
\hline$P-74$ & 6.13 & 259 & 30 & 46 & 31 & 26 & 7.0 & 8.0 & 4.0 & 0.2 & 36 & 0.15 & 3.0 & 164 \\
\hline$P-75$ & 6.92 & 316 & 25 & 66 & 20 & 31 & 3.0 & 8.0 & 7.0 & 0.1 & 48 & 0.03 & 4.0 & 177 \\
\hline P - 77 & 6.80 & 672 & 39 & 120 & 22 & 69 & 9.0 & 11 & 16 & 0.2 & 96 & 0.02 & 26 & 391 \\
\hline$P-78$ & 7.38 & 449 & 84 & 58 & 34 & 65 & 6.0 & 11 & 8 & 0.9 & 60 & ND & 7.0 & 294 \\
\hline $\mathrm{P}-81$ & 6.95 & 786 & 168 & 156 & 30 & 72 & 8.0 & 40 & 29 & 0.2 & 220 & ND & 4.0 & 519 \\
\hline$P-82$ & 6.12 & 288 & 20 & 72 & 7.0 & 30 & 3.0 & 11 & 8.0 & 0.9 & 60 & ND & 1.0 & 155 \\
\hline$P-83$ & 6.05 & 298 & 35 & 72 & 7.0 & 29 & 3.0 & 10 & 10 & 0.2 & 64 & ND & 1.0 & 168 \\
\hline$P-84$ & 5.95 & 743 & 44 & 149 & 40 & 69 & 11 & 22 & 31 & 0.1 & 184 & ND & 31 & 487 \\
\hline$P-88$ & 5.5 & 687 & 35 & 169 & 56 & 87 & 16 & 18 & 26 & 0.3 & 152 & 0.03 & 29 & 436 \\
\hline P - 89 & 6.4 & 599 & 59 & 183 & 39 & 76 & 12 & 24 & 21 & 0.6 & 148 & 0.03 & 4.0 & 420 \\
\hline$P-90$ & 4.7 & 556 & 15 & 155 & 46 & 73 & 11 & 11 & 19 & 0.1 & 108 & 0.02 & 16 & 347 \\
\hline P - 91 & 5.45 & 538 & 20 & 152 & 54 & 70 & 10 & 16 & 18 & 0.2 & 116 & 0.04 & 2.0 & 342 \\
\hline$P-92$ & 7.62 & 1348 & 89 & 385 & 49 & 127 & 13 & 75 & 56 & 0.2 & 420 & 0.03 & 7.0 & 802 \\
\hline P-93 & 4.71 & 726 & 19 & 169 & 62 & 91 & 25 & 13 & 29 & 0.5 & 152 & 0.06 & 29 & 430 \\
\hline P- 94 & 6.14 & 806 & 84 & 205 & 56 & 98 & 19 & 27 & 30 & 0.2 & 192 & 0.02 & 18 & 538 \\
\hline P- 95 & 5.17 & 447 & 15 & 135 & 43 & 64 & 11 & 6.0 & 16 & 0.4 & 84 & 0.04 & 3.0 & 295 \\
\hline P - 96 & 5.94 & 251 & 39 & 47 & 9.0 & 35 & 8.0 & 2.0 & 4.0 & 6.04 & 22 & 0.15 & 3.0 & 147 \\
\hline
\end{tabular}

Estudos Geológicos Vol. 28(2):2018

$\underline{\text { www.ufpe.br/estudosgeolgogicos }}$ 